disability. Gliedman and Roth (1976) in their highly influential paper 'The Grand Illusion: Stigma, Role Expectations and Communication' make the point that disability is above all else a social problem. The disabled are a minority group in society who have had and who still have to combat the attitude of society who regard them as 'other' or 'stranger'. All aspects of communication may be inhibited in a social sense; the disabled have to struggle not only with their innate handicap but with problems imposed upon them by society as do other minority groups (Jews, coloured minorities or majorities, homosexuals, drug addicts, etc.)

Within the correctly prescribed limits set by the author this is an admirable textbook which starts with infancy, describes the range and variations of development from 1 to 5 years of age and of older children. There are individual chapters on sensory, motor and intellectual development. The book closes with a valuable chapter on the work of the developmental paediatricians. It is again not a criticism of the text as defined that it is mainly concerned with diagnosis and the technical aspects of treatment, but there is a need for those who read the book to understand that the service which the handicapped child and his family desperately need extends far beyond these limits especially in terms of family support and integration of the handicapped child and his family into normal society. There are approximately 10 million children aged $0-15$ years in England of whom 1.5 million have a defect or disability. Not all of these are "handicapped' and there are many others of them who with better management need not have been so. Even so, they constitute a minority group of considerable magnitude. There are sound economic reasons why society should devote more attention to them. Professor Holt's book sets out the scientific basis upon which much of this help must be based.

This text, as have all the other books in this series, has been impeccaby edited and produced.

\section{Encyclopaedic Handbook of Medical Psychology}

Edited by StePhen Krauss. Pp. 585, hard cover. Butterworth Group, London, 1976. £13.00.

It was Stephen Krauss's life-long ambition to generate an encyclopaedia of medical psychology; a collection of authoritative statements on subjects $A-Z$ covering such diverse areas as accident proneness, adolescence, adoption, affective disorders, aggression, agnosia, alcoholism, amnesia, analytical psychology, anorexia nervosa, anxiety, aphasia, and so on. In the end he has succeeded in producing this worthwhile volume which fills a gap and is for the most part eminently readable and suitable also for browsing. Most contributions take the right form-a page or two summarizing the situation. A few authors only have surrendered to the impulse to swamp the item concerned with their own research data.

The editor was a knowledgeable and wise man, especially in the fields of neuropathology and existential philosophy. His sympathies in this respect have generated a number of continental contributions, especially German, which are refreshing to the eye and mind. Sadly, Dr Krauss died before the publication date but he was already confident that his publishers and admirers would follow through and complete the task to the best of their ability. The publishers, in particular, are to be congratulated in this respect and also on the style of the book. It merits a place on library bookshelves as a reference volume, so that those in the fields of psychiatry and medical psychology can have ready access and a clear introduction to these fields.

\section{Genetic Engineering: Threat or Promise?}

By Laurence E. KarP. Pp. xviii +235 , illustrated, hard cover. Nelson-Hall, Chicago, 1976. \$15.00.

'Genetic engineering' is a popular term which has been used with widely differing meanings. Dr Karp, a practising medic geneticist, uses it in the widest possible sense to refer bot $\$$ to various manipulative procedures in reproduction and to genetic counselling and screening with the many techniques; involved in genetic diagnosis whether pre- or post-natal.

The term is often used in a more restricted sense to refer $\frac{7}{8}$ experimental procedures involving DNA recombination also often termed genetic manipulation. The voluntary corp trol of such experiments has recently been the subject $\bar{s}$. recommendations by the Medical Research Council io⿱ Britain and the National Institutes of Health in the Unitef States. In the United States these recommendations and the introduction of statutory controls are currently the subject of intense controversy. Unfortunately, this may mislea $\mathbb{P}$ potential readers as to the subject of the book as Dr Kar $\overrightarrow{\mathrm{p}}$ devotes only one twenty-fifth of the text to this morg restricted form of genetic engineering.

The book is aimed at the 'layman' seeking guidance on the factual basis and implications of the procedures covere under this portmanteau term of genetic engineering. It is written in two main parts, preceded by a brief elementart introduction to the principles of human genetics. Part $\$$ covers such established fields as genetic counselling, genetriv screening, prenatal diagnosis of genetic disorders, the therapg of genetic disease and the controversial topic of eugenics Part II is devoted to those new procedures that are mors usually regarded as genetic engineering. These includes predetermination of the sex of offspring, in vitro fertilizatiog and such futuristic topics as parthenogenesis, cloning and th: synthesis of life from non-living matter.

The section on genetic counselling emphasizes the impore ance of a correct diagnosis to the advice given and comes. down firmly in favour of relevant information being give the patient and never withheld as, for example, not tellingano $X Y$ woman her true sex chromosome constitution Britain we would see the family doctor and hospital cono sultant, within his own speciality, as undertaking a good dea of genetic counselling whereas Dr Karp from his side of th즁 Atlantic sees such counselling as being provided by th trained clinical geneticist.

He then goes on to discuss the severe limitations on an尺 practical form of eugenics although he does not point out that genetic counselling, especially for dominant and $X \frac{0}{3}$ linked traits, has a small eugenic spin-off when the interest of the individual family coincides with that of the communit He does discuss very briefly the far more promising approach. of environmental manipulation to modify mutation rate of the expression of harmful genes. He includes protectio against mutagens, the use of prostheses, drug therapy and the prevention of haemolytic disease of the fetus due to Rhesus incompatibility. This aspect is further discussed in the chapter on genetic therapy where he clearly refutes the common false belief that genetic disorders are not treatable? This theme is illustrated by dietary and drug therapy, surgero and the prevention of inherited idiosyncratic response t $\vec{\sigma}$ drugs. These are followed by a section on specific replacemen therapy including insulin, clotting factor VIII, vitamins. acting as co-enzymes and enzyme replacement. Dr KarR touches on the possibilities for organ transplantation as $\$$ form of replacement therapy once the major problem of immune rejection has been overcome. He also, under the heading of genetic therapy, briefly discusses gene modifie cation or genetic engineering in its restricted sense as potential future technique.

A further chapter deals with genetic screening, covering screening of the newborn for phenylketonuria, carrie detection, screening for diabetes and hypertension in adults? and chromosomal screening. The general criteria and practicato problems of screening programmes are adequately out lined. The final chapter of the first part deals with prenatad diagnosis of genetic disease. 